\title{
Carved Monge Surfaces as New Forms in the Architecture
}

\author{
Jevgenija Filipova , Marina Rynkovskaya \\ Peoples' Friendship University of Russia, Engineering Department, 117198, Miklukho-Maklaya Str., 6, Moscow, Russia
}

\begin{abstract}
On the example of today's existing buildings and cities the tendency of using thin construction in modern world can be clearly noticed. To create new ideas and images engineers have to study new geometrical forms and its calculation methods. The article deals with carved Monge surface. The possibilities of its usage in the architecture, its geometry and form making are well examined in the article, and are the basic problems considered in the article. As well as the basic calculations of Monge surface were made in this article using moment less theory and finite element method, and we can clearly see the advantages of using this shell. The main aim of this article is to show the relevance of carved Monge surface.
\end{abstract}

\section{Introduction}

Nowadays for development and creation of the new urbanistic cities designers need to pay more and more attention to such tendencies in the construction which allow us to use more expressive architectural images, to cut the consumption of materials, labor input of production and installation of designs, as well as to solve important functional problems. In this regard the efficiency of space structures' usage is indisputable. But one shouldn't pay attention only to architectural expressiveness of shell of difficult geometry [1]. It should be noted that the shells allow to achieve the reliable designs with big stiffness, stability and durability with rather small consumption of materials. Changing various geometrical parameters of a shell, it is possible to vary over a wide range of fields of movements and tensions of construction [2]. Therefore, research of thin structures of uncanonical forms is in demand and can have a practical usage [3].

Nowadays different shell structures are used in different industries (shipbuilding, aircraft industry, automotive engineering, etc.), in civil engineering and architecture [4].

\section{Main features of carved Monge surface}

The usage of shape structures in different buildings is possible due to well-studied geometry, the existing theories of calculations, usage of computers and software. However, the majority of shape structures used nowadays are limited to number of surfaces only: circular cylindrical, conical, spherical and some other traditional shapes. These surfaces are just a small part of geometrical forms available by geometry [1, 3-12].

One of the directions in structural theory of thin constructions is a detailed study of geometry, new calculation methods of shells of uncanonical forms and research of the correlation between thin structure shape and its strength properties [13]. Therefore we would like to touch the less studied surfaces which have no less architectural expressiveness and other advances than different well known shell structures.

Great opportunities in creation of new architectural forms are given by carved Monge shell. These surfaces are rather technological and allow simplifying construction process due to ability of their middle surface to wrap on the surfaces without folds and gaps [14].

Concerning a shell structure it is necessary to announce several subjects of research: form making, geometrical characteristics, architectural features, possibility of its usage in modern buildings, and also methods of strength calculation.

\subsection{Architectural features of carved Monge surface}

Speaking about relevance of ruled carved Monge surface usage, it is necessary to examine architectural aspect. This surface can be used in solution of the most modern tendencies and questions of design today. First of all, shell structure, as an esthetic form, serves as a spectacular example of modern architecture. Its smooth and flexible forms, reflects to today's world tendencies. Secondly, the structure is an effective from the economic point of view. As the shell structure is a complete construction and works like an integrated construction, it does not require massive bearing walls. Thirdly, it is ability to seal big areas, and also the lack of the additional columns, cutting space.

If we speak about practical usage of this shell structure, it should be noted, that it is possible to use it as an independent bearing construction (showrooms, places for events with a big flow of people and others), and also as an additional form 
for different buildings integral characters creation (canopy, architectural details and others) [15].

Speaking about the usage of carved Monge surfac in the modern architecture, they are at the initial stage of introduction in modern architecture, because they are not so well studied. Nevertheless, it is possible to carry some existing buildings and constructions to carved Monge surface. As the example: Hydroelectric Tidal House - project made by Serbian architect (Fig. 1).

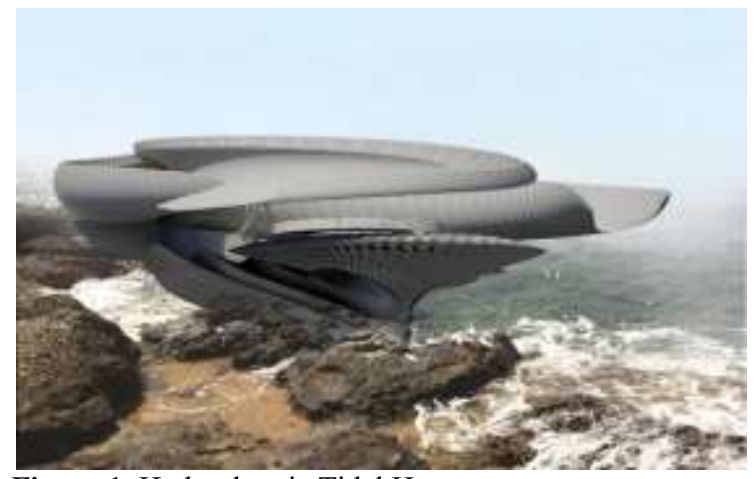

Figure 1. Hydroelectric Tidal House

\subsection{Geometry of carved Monge surface}

Speaking about form making, it is necessary to discuss the main methods of creation and also the mathematical description of this surface [16].

Gaspard Monge has given the definition of carved surfaces as the surfaces formed by the movement of the flat curve lying in the plane roll without sliding on some cylindrical surface (Fig. 2).

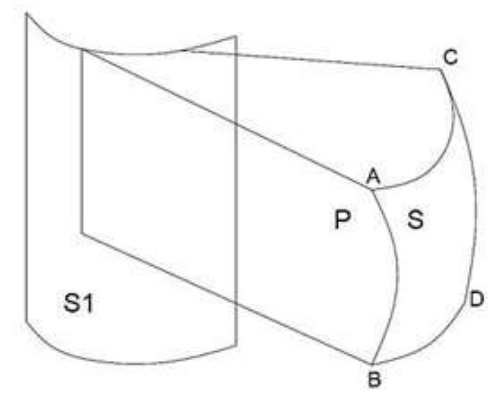

Figure 2. Form making method of carved Monge surface.

Speaking about geometry, we would like to begin with defining the equations of surface.

The general vector equation of a carved surface looks as follows:

$$
\overline{\mathrm{r}}=\bar{\rho}(\alpha)+\varphi(\beta) \overline{\mathrm{p}}(\alpha)+\psi(\beta) \overline{\mathrm{q}}(\alpha),
$$

where $\varphi(\beta), \psi(\beta)$ are the parametrical equations of the forming curve in mobile Cartesian reference system, $\bar{p}, \bar{q}$ are unitary vectors of mobile Cartesian reference system in the normal plane of the directing line $\bar{\rho}(\alpha)$.

There are more than 10 types of carved surfaces [17]. Depending on change of various parameters, for example the form of a moving line or a guiding line, the appearance of a surface will change (figs. 3- 5). Let us have a look on a specific case: ruled carved Monge surface (fig. 5). In this example, we accept an involute of circle as a parallel and an intercept as the meridian (fig. 6).

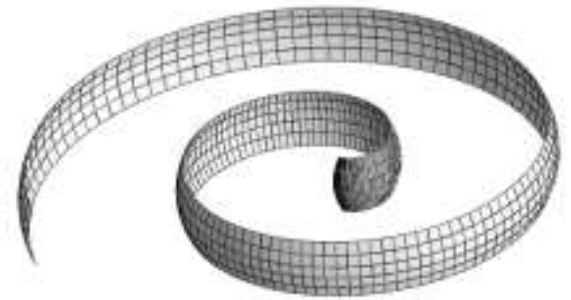

Figure 3. Carved Monge shell with cylindrical guide surface and parabola as a longitude.

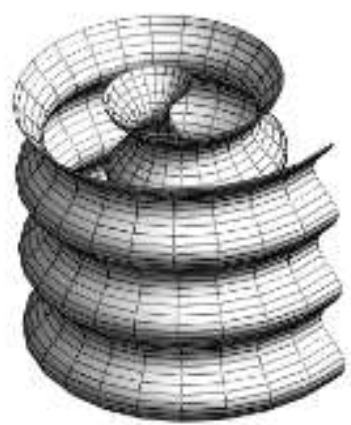

Figure 4. Carved Monge shell with cylindrical guide surface and sinusoid as a longitude.

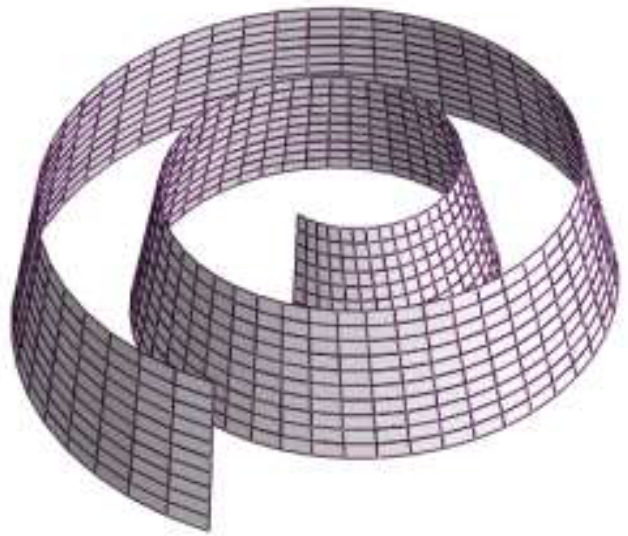

Figure 5. Carved ruled Monge shell with circularcylindrical guide surface.

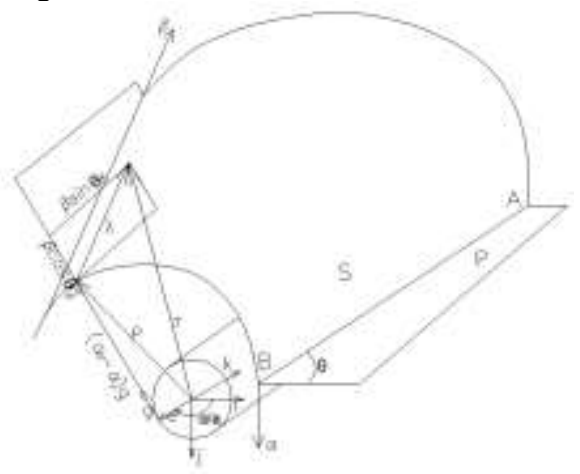

Figure 6. Carved ruled Monge shell assignment.

Vector equation (1) of a special case of ruled carved Monge surface can be presented :

$$
\begin{gathered}
\mathrm{r}(\alpha, \beta)=\mathrm{a} \cdot \overline{\mathrm{e}}+\left(\alpha_{0}-\alpha+\beta \cdot \cos (\theta)\right) \cdot \overline{\mathrm{g}}+\beta \cdot \\
\sin (\theta) \cdot \overline{\mathrm{k}}
\end{gathered}
$$


where, $e, g$ are vector circular functions; $\rho=a \cdot e+$ $\left(\alpha_{0}-\alpha\right) \cdot g$ is the equation of a parallel, which represents itself the involute of circle with radius $r=a$; $\alpha$ is natural parameter; $\beta=|\lambda|$ is binormal of a guide line, $\theta$ is a corner between the vectors $g$ and $\lambda ; \alpha_{0}$ is initial point unwrapping of a surface, $\lambda=\beta \cdot \cos (\theta) \cdot g+\beta \cdot \sin (\theta) \cdot k$ is the meridian equation in any situation.

Let us change a vector way of equations representation to a parametrical one.

Formulas (2) give the chance to receive the parametrical equations of the considered surface:

$$
\begin{gathered}
X=a \cdot \cos \left(\frac{\alpha}{a}\right)+\alpha_{0} \cdot \sin \left(\frac{\alpha}{a}\right)-\alpha \cdot \sin \left(\frac{\alpha}{a}\right)+ \\
\cos (\theta) \cdot \sin \left(\frac{\alpha}{a}\right) \cdot \beta, \\
Y=-a \cdot \sin \left(\frac{\alpha}{a}\right)+\alpha_{0} \cdot \cos \left(\frac{\alpha}{a}\right)-\alpha \cdot \cos \left(\frac{\alpha}{a}\right)+ \\
\cos (\theta) \cdot \cos \left(\frac{\alpha}{a}\right) \cdot \beta, \\
Z=\sin (\theta) \cdot \beta .
\end{gathered}
$$

Curvilinear coordinate $\alpha$ coincides with a surface parallels, and $\beta$-lines - its lineal moving line. Then the main quadratic forms coefficients of a surface and main curvatures are determined by formulas:

$$
\begin{aligned}
& \qquad \begin{array}{l}
A=\frac{\left(\alpha_{0}-\alpha+\beta \cdot \cos (\theta)\right)}{a}=C_{0}+C_{1} \cdot \alpha+C_{2} \cdot \beta ; \\
B=1 ; \\
L=\frac{-A \cdot \sin (\theta)}{a} ; \\
F=M=N=0 ; \\
\quad k_{1}=\frac{\sin (\theta)}{a \cdot A} ; k_{2}=0,
\end{array} \\
& \text { where } C_{0}=\frac{\alpha_{0}}{a} ; C_{1}=-\frac{1}{a} ; C_{2}=\frac{\cos (\theta)}{a} .
\end{aligned}
$$

\section{Methods of strength analysis}

Let us look at the main initial methods of strength analysis for checking their correctness in relation to this shell structure.

The momentless theory represents simplified option, where influence of bending moment, torque moment and transverse force on the stress strain behavior is not considered (Fig.7). Nowadays momentless theory is not so popular, but still there are some works which take momentless theory as the basic calculation method, such as [18-20].

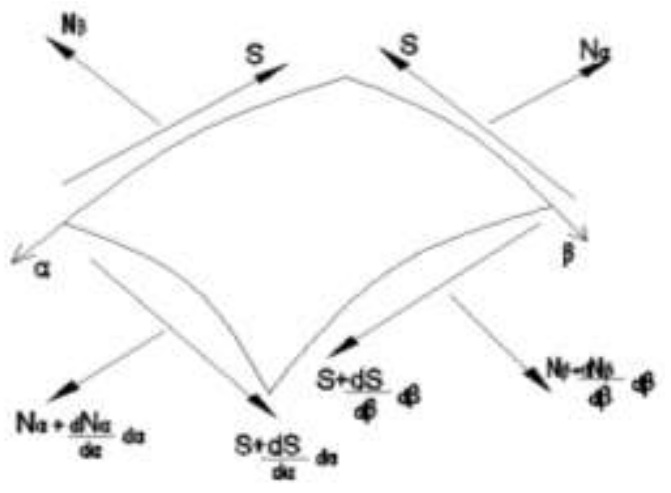

Figure 7. Efforts in the momentless theory

The equations of the momentless theory for a carved Monge shells with circular-cylindrical guide surface will be:

$$
\begin{gathered}
\frac{\partial N_{\alpha}}{\partial \alpha}+\frac{1}{A} \cdot \frac{\partial}{\partial \alpha}\left(A^{2} \cdot \mathrm{S}\right)+\mathrm{A} \cdot \mathrm{X}= \\
\frac{\partial}{\partial \beta}\left(\mathrm{A} \cdot N_{\beta}\right)-\frac{\partial A}{\partial \beta} \cdot N_{\alpha}+\frac{\partial S}{\partial \beta}+\mathrm{A} \cdot \mathrm{Y}=0 ; \\
\frac{N_{\alpha}}{R 1}-Z=0
\end{gathered}
$$

where, $N_{\alpha}$ is normal force in the direction $\alpha, N_{\beta}$ is normal force in the direction $\beta, S$ is shearing force, $\mathrm{X}, \mathrm{Y}, \mathrm{Z}$ are projections of the spreaded load on the directions $\alpha, \beta, z$.

Will enter new constants [18]:

$$
\begin{aligned}
& m=\frac{a}{\sin (\theta)} ; C_{0}=\frac{\alpha_{0}}{a} ; \\
& C_{1}=-\frac{1}{a} ; C_{2}=\frac{\cos (\theta)}{a} .
\end{aligned}
$$

Integrating the equation (5) we receive:

$$
\begin{gathered}
N_{\alpha}=m \cdot A \cdot Z \\
S=-\frac{1}{A^{2}} \int_{\beta 0}^{\beta} A \cdot\left(A \cdot X+\frac{\partial N_{\alpha}}{\partial \alpha}\right) \partial \beta+\frac{x 1(\alpha)}{A^{2}} \\
N_{\beta}=-\frac{1}{A} \int_{\beta 0}^{\beta}\left(A \cdot Y-\cdot C_{2} \cdot N_{\alpha}+\frac{\partial S}{\partial \alpha}\right) \partial \beta \\
+\frac{x 2(\alpha)}{A}
\end{gathered}
$$

Let's consider an example of a dead load action.

So $\mathrm{X}=0 ; \mathrm{Y}=\mathrm{q} \cdot \sin (\theta), \mathrm{Z}=-\mathrm{q} \cdot \cos (\theta)$.

Integrated equations (6) will look:

$$
\begin{aligned}
N_{\alpha} & =-\frac{a}{\sin (\theta)} \cdot A \cdot q \cdot \cos (\theta), \\
S & =-\frac{1}{A^{2}} \cdot\left(\frac{1}{3} C_{2}^{2} \cdot X \cdot \beta^{3}+\frac{1}{2} \cdot C_{2} \cdot(2 \cdot)\right) \\
& +\frac{f 1(\alpha)}{A^{2}}
\end{aligned}
$$

In the results we will receive the following diagrams of normal efforts $N_{\beta}$ and $N_{\alpha}$, and shearing force $S$ (Fig. 8-10).

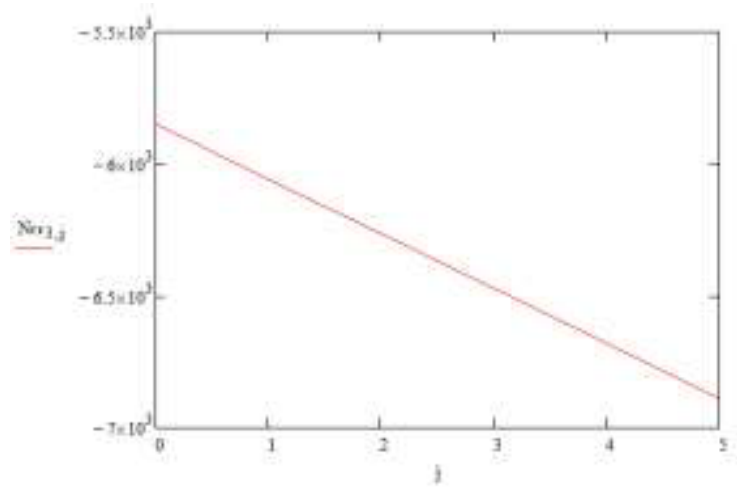

Figure 8. Diagram $N_{\alpha}$ where $\alpha=-2 \pi$.

Now we will consider the turned-out results of the calculation of a carved Monge surface by finite element method. For calculation purposes the design model has been created using computer program LIRA 2013R (fig. 11). Nowadays different computer programs are the most popular and easiest way of calculation [21, 22], but analytical methods are still in usage too [23]. All the parameters were accepted the same as for the momentless theory. The accepted shell thickness is $50 \mathrm{~mm}$. Examine the same option 
of a dead loads similar to the momentless theory. We will receive izofields of internal forces and movements (Fig. 12).

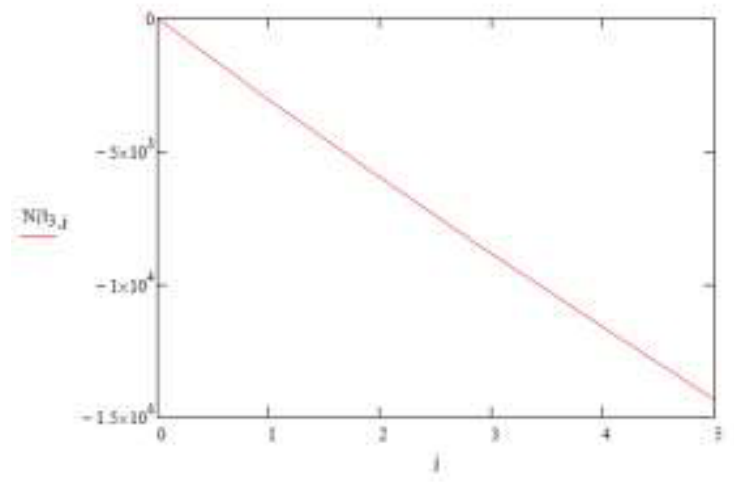

Figure 9. Diagram $N_{\beta}$ where $\alpha=-2 \pi$.

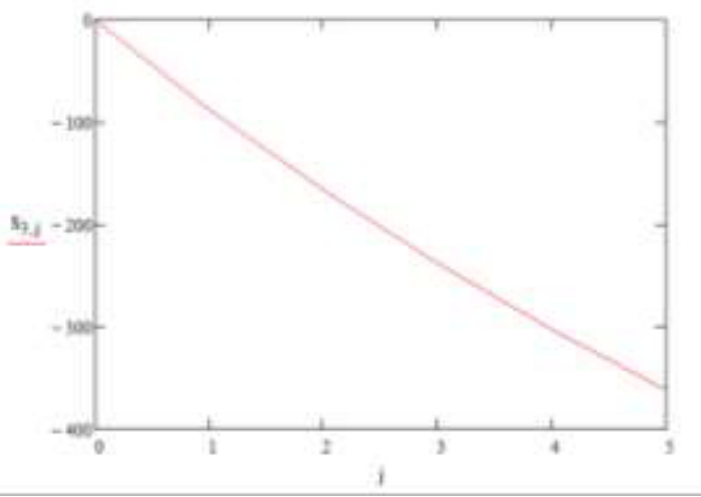

Figure 10. Diagram $S$ where $\alpha=-2 \pi$.

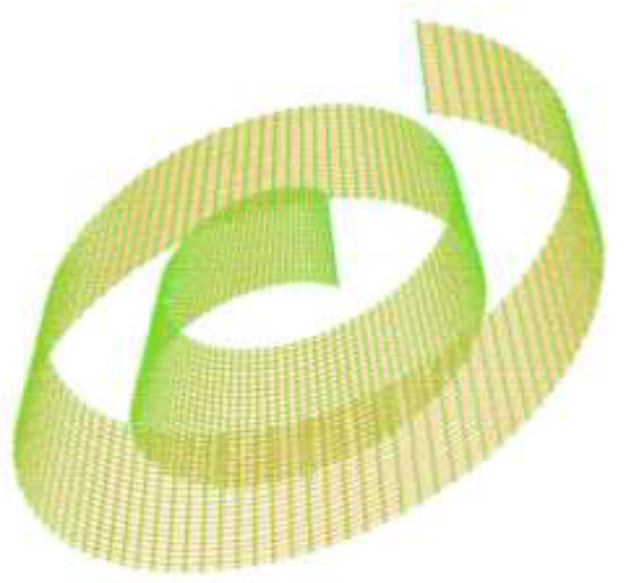

Figure 11. General view

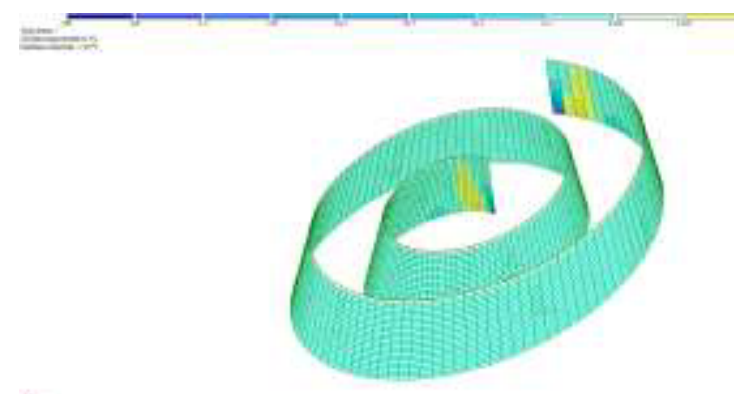

Figure 12. Izofield of $N_{\beta}$
To compare with the momentless theory we will analyze normal efforts $N_{y}, N_{x}$ and shearing force $S$. For the analysis of the calculations made, we will make the table of normal efforts $N_{\beta}, N_{\alpha}$ and the shearing force counted by a momentless method and by finite element method where $\alpha=-$ $2 \pi$ and calculate differences in the results (table 1).

Table 1. Comparison of two calculation methods.

\begin{tabular}{|c|c|c|c|}
\hline & \multicolumn{3}{|c|}{$\alpha=-2 \pi$} \\
\hline $\mathrm{N} \beta$ & $\begin{array}{l}\text { momentless } \\
\mathrm{kg} / \mathrm{m}\end{array}$ & $\mathrm{FEM} \mathrm{kg} / \mathrm{m}$ & $\begin{array}{l}\text { difference } \\
\%\end{array}$ \\
\hline$\beta=-6$ & 0.00 & -0.40 & - \\
\hline$\beta=-4.5$ & -3.80 & -4.12 & 7.8 \\
\hline$\beta=-3$ & -7.44 & -8.09 & 8.1 \\
\hline$\beta=-1.5$ & -10.95 & -11.75 & 6.8 \\
\hline$\beta=0$ & -14.34 & -14.53 & 1.3 \\
\hline $\mathrm{N} \alpha$ & $\begin{array}{l}\text { momentless } \\
\mathrm{kg} / \mathrm{m}\end{array}$ & $\mathrm{FEM} \mathrm{kg/m}$ & $\begin{array}{l}\text { difference } \\
\%\end{array}$ \\
\hline$\beta=-6$ & -5.85 & -6.28 & 6.9 \\
\hline$\beta=-4.5$ & -6.11 & -6.72 & 9.1 \\
\hline$\beta=-3$ & -6.37 & -6.90 & 7.7 \\
\hline$\beta=-1.5$ & -6.63 & -7.37 & 10.1 \\
\hline$\beta=0$ & -6.89 & -7.42 & 7.2 \\
\hline $\mathrm{S}$ & $\begin{array}{l}\text { momentless } \\
\mathrm{kg} / \mathrm{m}\end{array}$ & $\mathrm{FEM} \mathrm{kg} / \mathrm{m}$ & $\begin{array}{l}\text { difference } \\
\%\end{array}$ \\
\hline$\beta=-6$ & 0.00 & -11.27 & - \\
\hline$\beta=-4.5$ & -107.85 & -110.60 & 2.5 \\
\hline$\beta=-3$ & -202.76 & -215.42 & 6.2 \\
\hline$\beta=-1.5$ & -286.71 & -278.51 & 2.9 \\
\hline$\beta=0$ & -361.34 & -316.92 & 12.3 \\
\hline
\end{tabular}

As we can see in results, the difference between two methods of calculation is not so big. An average difference is between $5 \%-10 \%$ (percent). It is a positive result because the finite element method includes such important things as bending moment, torque moment and transverse force, which influence the construction work.

\section{Conclusion}

Carved Monge surfaces, as it was shown earlier, have the following advantages as:

1. architectural expressiveness,

2. the reliable design with high stiffness and durability,

3. rather small consumption of materials (massive bearing walls aren't required),

4. technological effectiveness of construction that allows to carry out construction process directly on a building site,

5. possibility of rational use of space,

6. presence of smooth lines pleasant for eye perception,

7. an opportunity to use shell for buildings of different functions.

Also the analysis of two calculation methods was made, and the results show us that calculations are correct, as the average difference in two methods is in limits of error.

\section{References}


1. Roberto Cipolla, Peter Giblin. Visual Motion if Curves and Surfaces, Cambridge University Press, UK, 187 p (2001).

2. Deserno M. Notes on differential geometry with special emphasis on surfaces in R3, UCLE, Los Angeles, 2004. - p. 64.

3. Ivanov V.N., Rynkovskaya M.I. Application of circular surfaces to the architecture of the buildings, structures and products. Bulletin of PFUR: Engineering Researches, 3, p.111-119 (2015).

4. Rynkovskaya M. On application and analysis of helicoidal shells in architecture and civil engineering, Bulletin of PFUR, engineering, 4, p. 84-90 (2012).

5. S.N. Krivoshapko, Geometry and strength of general helicoidal shells, 5, p. 161-175, (1999).

6. S.N. Krivoshapko, V.N. Ivanov, Encyclopedia of Analytical Surfaces, Springer International Publishing Switzerland, 752 p (2015).

7. C.A. Bock hyeng., S.N. Krivoshapko Umbrella-type surfaces in architecture of spatial structures, IOSR JOURNAL OF ENGINEERING, 3, p. 43-53 (2013).

8. R. Bradshaw, D. Campbell, M. Gargari, A. Mirmiran, P. Tripeny, Special structures. Past, present, and future, Journal of Structural Engineering, p. 691-701 (2002).

9. S.N. Krivoshapko, Cable-stayed structures, Structural Mechanics of Engineering Constructions and Buildings, 1, p. 9-22, (2016).

10. V.N. Ivanov. The problems of the geometry and the architectural design of shells based on cyclic surfaces, Spatial structures in new and renovation projects of buildings and construction, Proceedings international congress ICSS-98, 2, - p. 539-546 (1998).

11. Hyeng, A. Christian Bock, E.B. Yamb, Aplication of cyclic shells in the architecture, machine design, andbioncs, Int. Journal of Modern Engineering Researches 12, 799-806, (2012).

12. S.N. Krivoshapko, K.P. Pjatikristovsky. On history of building of wooden shells and their opportunities at present and in the future, Structural Mechanics of Engineering Constructions and Buildings, 1, p. 3-18, (2014).
13. S.N. Krivoshapko. Static analysis of shells with developable middle surfaces, Applied Mechanics Reviews, 51, No12, Part 1, p. 731-746 (1998).

14. Barony S.Y., Tottenham H. The analysis of rotational shells using a curved ring element and the mixed variational formulation II Int. J. Numer Meth. Eng.10. N4, p.861-872 (1976).

15. V.N. Ivanov, R. Muxammad, Geometry of carved Monge surface and shell structuring, Structural Mechanics of Engineering Constructions and Buildings, 1, p. 27-36, (2002).

16. Olodo E.T., Adjovi E.C., Krivoshapko S.N. Geometrical modeling of a composite folded membrane by a developable membrane with parabolic guidelines of any order// International Journal of Scientific \& Engineering Research, 4. p. 338-343, (2013).

17. Luther Pfahler Eienhart. A Treatise on the Differential Geometry of Curves and Surfaces, Dover Publicans, New York, 479 p (2004).

18. Arbelaes, Juxanio Marulanda, Analysis of Shells in the Form of Ruled Monge surface, PhD Diss. In technic., Moscow, UDN, p. 154, (1970).

19. M.J. Fares, Momentless theory of carved Monge surface of double curvature, p.118 (1974)

20. Krivoshapko S.N., Gbaguidi Aïssè Gerard. Two methods of analysis of thin elastic open helicoidal shells// International Journal of Research and Reviews in Applied Sciences, 12, p. 382-390, (2012).

21. Bathe K.J. Numerical Methods in finite element analysis-prentice-hall, Englewood Cliffs, New Jersey, p. 631, (1976).

22. Bushel 1 D. Computer analysis of complex shell structures II Pres. At AIAA eight Aerospace sci. Meet.N.Y.AJAA paper, 70, p. 138, (1970).

23. Rynkovskaya M.I. On problem of strength analysis of thin linear helicoidal shells, Structural Mechanics of Engineering Constructions and Buildings, 6, p. $13-15,(2015)$ 